5. Яковлева В.С. Методы измерения плотности потока радона и торона с поверхности пористых материалов: монография / В.С.Яковлева; Томский политехнический университет. - Томск: Изд-во Томского политехнического университета, 2011. - 174 с.

\title{
Расчет усиления железобетонного моста композитными материалами совместно с полимерной пропиткой
}

Хрюкин А.А., магистрант, Северо-Восточный федеральный университет, 2. Якутск E-mail: $\underline{\text { hr-art@mail.ru }}$

Научный руководитель: старший преподаватель Смолина М.В.

Введение. Мосты являются важнейшими элементами транспортной инфраструктуры страны, и повышение их надежности стоит одной из основных задач эксплуатации дорожной сети.

Мосты подвержены различным воздействиям: выщелачиванию бетона, образованию трещин и сколов бетона, коррозии металла, деформации и разрушению элементов от проходящего транспорта, которые постепенно снижают прочность и эксплуатационную надежность мостов. Происходит физический износ, ограничивающий срок их службы. Кроме физического износа, происходит моральное отставание мостов от возрастающих требований транспорта в связи с увеличением нормативных расчетных нагрузок и скоростей движения. [1]

На сегодняшний день многие пролетные строения железобетонных мостов, ввиду длительных сроков и суровых условий эксплуатации, имеют дефекты и повреждения, прямо или косвенно влияющие на их грузоподъемность. [2] В виду этого возникает острая необходимость в усилении мостов.

В практике усиления железобетонных мостов известен ряд традиционных методов, таких как усиление шпренгельными тяжами, увеличение поперечного сечения и др. Однако в настоящее время широко используется технология усиления с применением не подверженных коррозии композитных материалов на основе углеродных волокон. Их использование при усилении позволяет увеличить несущую способность главных балок пролетного строения. [3] Но грузоподъёмность моста зависит не только от несущей способности главных балок пролетного строения, но и от прочности плиты проезжей части. Плита проезжей части представляет собой конструкцию из главных балок, объединённых между собой швами омоноличивания. Данные швы являются наиболее слабым звеном в пролетном строении. Вода, проникающая сквозь нарушенную гидроизоляцию подвергает выщелачиванию и деградации бетона швов, тем самым уменьшая их прочность.

Вследствие этого актуальным вопросом является проектирование комплексного усиления железобетонных мостов, включающего в себя увеличение несущей способности главных балок пролетного строения и восстановление прочности бетона швов омоноличивания плиты проезжей части. 
Целью работы является расчет усиления железобетонного моста композитными материалами совместно с использованием полимерной пропитки восстанавливающей прочность бетона, а также определение эффективности использования данных методов усиления.

Материалы и методы исследования. Объектом исследования является мост через р. Былыгы на км 359+189 автомобильной дороги «Колыма» Якутск - Магадан в Республике Саха (Якутия). Мост запроектирован под нагрузки А11, НК-80 по схеме (2х11.40), полная длина моста 24.93 м. Пролётное строение - балочно-разрезное, разработано по серии 3.503.1-73. Балки пролетного строения - ребристые без диафрагм, с железобетонной плитой в составе основной несущей конструкции проезжей части.

В целях определения фактической грузоподъемности моста произведен расчет прочности несущих конструкций по нормальным и наклонным сечениям в соответствии с положениями СП 35.13330.2011, ОДМ 218.4.026-2016. Грузоподъемность с учетом фактических размеров конструкций и выявленных дефектов по данным обследования 2013 года была рассчитана на существующие нормативные нагрузки по схеме «АК» в соответствии с ГОСТ Р 52748-2007.

Результаты расчетов показали, что предельный изгибающий момент составляет $\mathrm{M}_{\text {пред }}=990,81$ кНм, предельная поперечная сила $-\mathrm{Q}_{\text {пред }}=486,67$ кН. Фактические классы нагрузок составляют $K_{\mathrm{AK}}=13,3$; $\mathrm{K}_{\mathrm{HK}}=9,52$, что не соответствует нормативному классу нагрузки $\mathrm{K}=14$.

Грузоподъемность моста снижена ввиду присутствия таких дефектов, как: выщелачивание цементного камня и деградационные разрушения швов омоноличивания плиты проезжей части, износ покрытия проезжей части, разрушение и выключение из работы переходной плиты.

Для расчета усиления, принята технология повышения несущей способности железобетонных конструкций с использованием композитной ткани на основе углеволокна. Технология предполагает наклеивание высокопрочной композитной ткани на поверхность усиливаемой конструкции с помощью эпоксидных компаундов. Увеличение несущей способности достигается за счет включения композитного материала в совместную работу с балкой на изгиб при воздействии временной нагрузки (рис 1.)

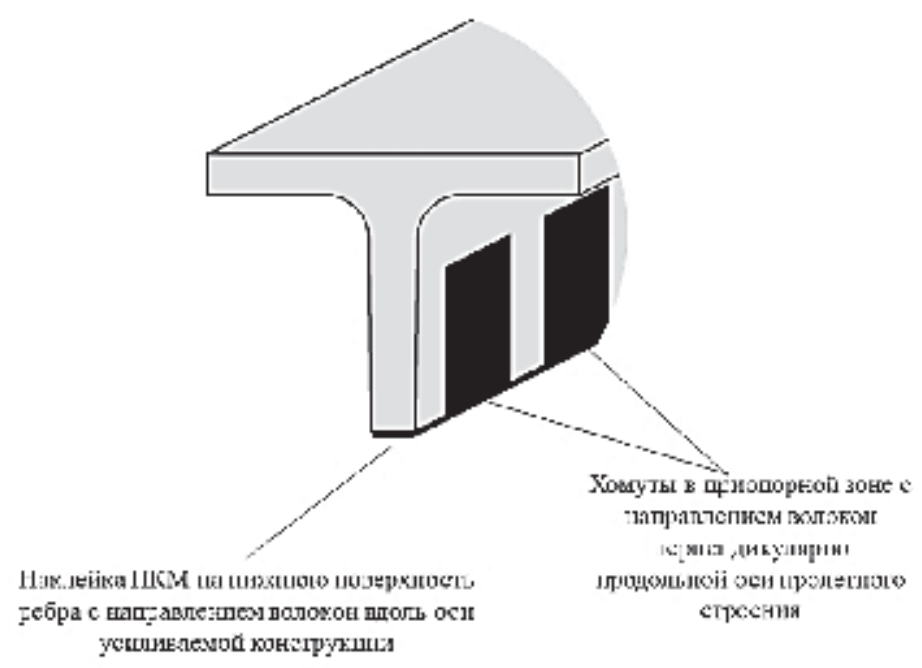

Рис. 1. Конструкция усиления внешним армированием композитными материалами 
Основанием для усиления конструкций являются результаты расчёта эксплуатируемой конструкции по прочности нормальных и наклонных к оси балки сечений. Расчётами устанавливают недостающее значение несущей способности, по которому определяют требуемое сечение (количество слоёв ткани) наклеиваемого композиционного материала, а именно: $\Delta \mathrm{M}$ - недостающее значение изгибающего момента; $\Delta \mathrm{Q}$ - недостающее значение поперечной силы.

Расчеты выполнены в соответствии с положениями ОДМ 218.3.027-2013.

Площадь сечения лент в середине пролета определяется из выражения:

$$
F_{k} \geq \frac{M}{0,9 \cdot g_{k}\left(n-\frac{x}{1,0}\right)} \cdot \frac{z_{k}}{z_{a}}
$$

Где, $\Delta \mathrm{M}-$ недостающая несущая способность, $\Delta \mathrm{M}=\mathrm{M}_{\mathrm{вp}}{ }^{\mathrm{HK}}-\left(\mathrm{M}_{\text {пред }}-\mathrm{M}_{\text {пост }}\right)=$ 1024.56 - $696.81=327.75$ кНм, где $\mathrm{M}_{\text {вр }}{ }^{\text {НК }}$ - наибольшее значение временной нагрузки.

$\mathrm{R}_{\mathrm{k}}$ - расчетное сопротивление композиционного материала растяжению, кПа;

h - высота балки, м;

$\mathrm{x}$ - расстояние от верха балки, до центра тяжести сжатой зоны бетона, м.

$\varepsilon_{\mathrm{k}}$ - относительно удлинение композиционного материла, $1,5 \%$.

$\varepsilon_{\mathrm{a}}-$ относительно удлинение арматуры, для ненапрягаемой арматуры 2,5\%.

$$
F_{\mathrm{k}}=\frac{327,75}{0,9+3103393 *\left(0,9-\frac{0,02,2}{1,0}\right)} * \frac{1,5}{2,5}=0,00008021 \mathrm{~m}^{2}=0,8021 \mathrm{~cm}^{2}
$$

Для усиления принята углеродная ткань FibARM Tape 530-300, шириной 15 см и толщиной 0,0294 см. Площадь сечения ткани составляет $\mathrm{F}_{\text {ткани }}=0,441 \mathrm{~cm}^{2}$

Поделив значение необходимой площади сечения на площадь сечения принятой ткани $\frac{F_{\mathrm{k}}}{\mathrm{F}_{\text {тканII }}}=\frac{0.8021}{0.441}=1.818$, получим, что для усиления балок пролетных строений и обеспечения им достаточной несущей способности необходимо 2 слоя углеродной ткани FibARM Tape 530-300, наклеиваемых на нижнюю поверхность ребер балок.

Необходимая длина лент усиления подбирается согласно таблице 4 ОДМ 218.3.027-2013 и составляет для первого слоя $\mathrm{L}=\mathrm{l}_{\mathrm{p}} / 2=11,4 / 2=5,7$ м, для второго слоя $\mathrm{L}=\mathrm{l}_{\mathrm{p}}=11,4$ м. Итого 17,1 м на одну балку.

Помимо усиления балок пролетных строений, необходимо обеспечить восстановление прочности бетона швов омоноличивания плиты проезжей части моста.

Для этого принят способ восстановления путем обработки бетонной поверхности полимерной пропиткой. При нанесении на поверхность бетона, она диффундирует в объем пор и отверждается там влагой воздуха, а также образует на поверхности прочную, химстойкую, водонепроницаемую пленку (рис. 2).

Для определения несущей способности плиты проезжей части выполнен расчет прочности по нормальным и наклонным сечения в соответствии с СП 35.13330.2011.

Расчет прямоугольного сечения производят из условия $\mathrm{M}^{\text {расчет }} \leq \mathrm{M}^{\text {пред }}$ для середины пролета плиты:

$$
\mathrm{M}^{\text {расчет }} \leq \mathrm{M}^{\text {пред }}
$$

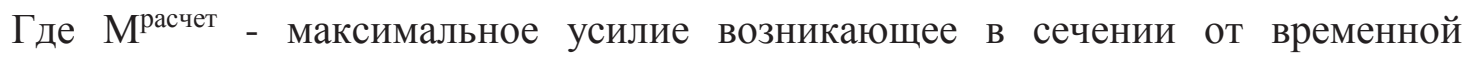

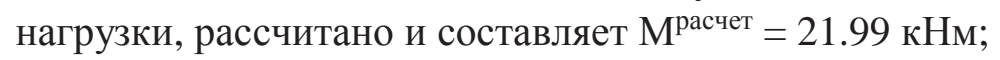

$\mathrm{M}^{\text {пред }}$ - предельный изгибающий момент воспринимаемый сечением;

Результаты расчета показали, что при фактическом классе бетона плиты проезжей части В27,5 условие прочности $\mathrm{M}^{\text {расчет }}=21.99$ кНм $>\mathrm{M}_{1}^{\text {пред. }}=12.5$ кНм, не выполняется. 
При фактическом классе бетона В27,5 марки М350 для достижения проектного класса В35 необходима обработка 5 слоями полимерной пропитки СИЛОР-Ультра КМ с расходом материала 0,250-0,450 кг/м2 - пропитывающий слой 0,150-0,200 кг/м2 последующий слой. При этом условие прочности $M^{\text {расчет }}=21.99 \kappa \mathrm{KM}_{\mathbf{M}}<\mathrm{M}_{2}^{\text {пред. }}=30.46$ кНм выполняется.

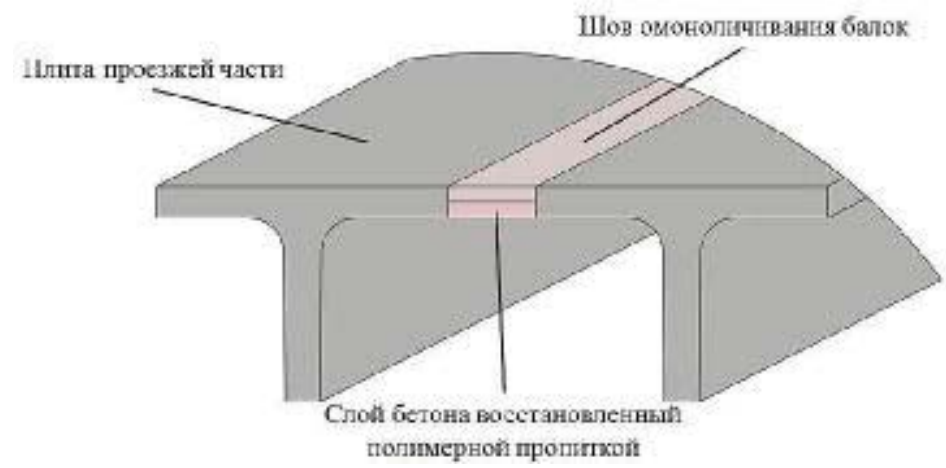

Рис. 2. Плита проезжей части в составе эксплуатируемого пролетного строения

Для технико-экономического обоснования применения вышеприведенных методов, рассчитано усиление несущих элементов шпренгельными тяжами. Расчет показал, что для усиления тяжами необходима сварная конструкция из пластины, с толщиной ребра 8 мм и шириной 20 мм по ГОСТ 103-2006 и уголок №2, с толщиной ребра 3 мм по ГОСТ 8509-93. При этом усилие воспринимаемое сечением балки совместно со стальным шпренгелем составляет $\mathrm{M}=1363.4$ кНм, что превышает максимальное значение усилия от временной нагрузки $\mathrm{M}_{\mathrm{вp}}=1024,56$ кНм.

Во всех вышеприведённых расчетах усиление на поперечные силы не требуется так как $\mathrm{Q}_{\text {пред }}=486,67$ кН больше значения $\mathrm{Q}_{\text {вр }}=401.48$ кН.

В целях определения стоимости ремонтных работ на мосту выполнен расчет сметной стоимости на программном комплексе WinRIK. Сметная стоимость усиления моста через р. Былыгы на км 359+189 автомобильной дороги «Колыма» по сводному сметному расчету составила в текущих ценах на IV квартал 2016 года:

- на усиление с помощью шпренгельных тяжей 200.232 тыс. руб.;

- на усиление тканевыми композитными материалами совместно с полимерной пропиткой 161.405 тыс. руб;

Заключение. Таким образом, усиление железобетонных пролетных строений моста через р. Былыгы тканевыми композитными материалами совместно с использованием полимерной пропитки позволит обеспечить достаточной уровень эксплуатационной надежности и долговечности мостового сооружения. При этом стоимость ремонтных работ по усилению, по сравнению с традиционным методом усиления металлическими шпренгельными тяжами меньше на 19,4\%.

Список литературы:

1. Дементьев В.А. Усиление и реконструкция мостов на автомобильных дорогах. - Воронеж: Воронеж. гос. арх.-строит. ун-т., 2006. - 116 с.

2. Неровных А.А. Совершенствование методики оценки грузоподъемности железобетонных пролетных строений железнодорожных мостов, усиленных 
композиционными материалами. Автореферат диссертации на соискание ученой степени кандидата технических наук. Новосибирск, 2013.

3. Овчинников И.Г., Валиев Ш.Н., Овчинников И.И., Зиновьев В.С., Умиров А.Д. Вопросы усиления железобетонных конструкций композитами: 1. экспериментальные исследования особенностей усиления композитами изгибаемых железобетонных конструкций // Интернет-журнал «Науковедение», 2012, №4, с.1-22. 